\title{
LA FOTOGRAFÍA COMO EXPRESIÓN DEL CONCEPTO
}

\author{
Arlindo Machado
}

Pontifícia Universidad Católica de São Paulo

De tanto en tanto, la discusión sobre la naturaleza más profunda de la fotografía vuelve a la superficie con insistencia. En esas ocasiones, todo lo que parecía sólido se disuelve en el aire. Dentro de algunas décadas, la fotografía cumplirá los dos siglos de existencia y, todavía entonces, estaremos tratando de entenderla. Estas dificultades tienen buenos fundamentos. La fotografía es la base tecnológica, conceptual e ideológica de todos los medios contemporáneos $\mathrm{y}$, por ese motivo, comprenderla, definirla, es un poco también comprender y definir las estrategias semióticas, los modelos de construcción y percepción, las estructuras en las que se sustenta toda la producción contemporánea de signos visuales y auditivos, sobre todo de aquélla que se hace a través de mediación técnica. Cada vez que se introduce un medio nuevo, éste sacude las creencias establecidas anteriormente y nos obliga a volver a los orígenes para revisar las bases a partir de las cuales edificamos la sociedad de los medios. La televisión y, por extensión, la imagen y sonido electrónicos, ya nos hicieron encarar esa indagación 
hace algunas décadas. Ahora, el procesamiento digital y la modelación directa de la imagen en la computadora nos enfrentan a nuevos problemas y nos hacen mirar retrospectivamente, en el sentido de revisar las explicaciones que hasta entonces sustentaban nuestras prácticas y teorías. En un momento como éste, en que la imagen y también el sonido pasan a ser sintetizados a partir de ecuaciones matemáticas y de modelos de la física, en un momento en que hasta el mismo registro fotográfico puede ser memorizado en forma numérica, es necesario revisar buena parte de nuestros paradigmas teóricos.

Hablando en términos de la teoría de los signos de Charles S. Peirce, la fotografía ha sido habitualmente explicada ya poniendo énfasis en su iconocidad (Cohen, 1989: 458; Sonesson, 1998), o sea, tanto en su analogía con el referente u objeto, como en sus cualidades plásticas particulares; ya enfatizando su indexicalidad (Dubois, 1983: 60-107; Schaeffer, 1987: 46-104), es decir, basándose en su conexión dinámica con el objeto (es el referente lo que causa la fotografía); o bien aceptando finalmente ambos énfasis al mismo tiempo (Santaella y Nöth, 1998: 107-139; Sonesson, 1993: 153-154). A pesar de eso, incluso admitiendo que muchos de los elementos codificadores de la fotografía pueden ser considerados arbitrarios y convencionales, prácticamente no existe una reflexión sistemática sobre la fotografía como símbolo, en el sentido peirceano del término, es decir, como la expresión de un concepto general y abstracto. Aunque algunos analistas hayan alertado ya sobre la necesidad de concebir la fotografía, sobre todo la contemporánea, «haciendo intervenir, de manera simultánea (y no exclusiva) las tres categorías peirceanas» (Carani, 1998), la verdad es que la concepción de la fotografía como ley o norma generalizadora constituye un desafío teórico. La única voz discordante en medio del consenso general parece haber sido la de Vilém Flusser, un pensador de la técnica que, ya en 1983, en una obra fundamental escrita bajo el impacto del surgimiento de las imágenes digitales, aseguró que la fotografía, más que simplemente registrar impresiones del mundo físico, en verdad traduce teorías científicas en imágenes. El pensamiento de Flusser, en ese sentido, es radical y sin concesiones: la fotografía puede tener muchas funciones y usos en nuestra sociedad, pero la razón de su existencia está en la materialización de los conceptos de la ciencia o, para usar palabras del propio autor, ella «transforma conceptos en escenas» (Flusser, 1985: 45). El objetivo de este artículo es discutir, partiendo de la consideración inicial de Flusser y basándonos en las nuevas referencias apuntadas por las imágenes digitales, algunos de los argumentos y razones que 
a nuestro entender autorizan el reposicionamiento de la fotografía en ese terreno que Peirce clasificó como tercero en su escala semiótica, el terreno del concepto.

Durante un viaje que hice a la Patagonia argentina, hace algún tiempo, me llamó la atención la increíble e infinita variedad de verdes del paisaje. Jamás podía imaginar que ese simple color que llamamos «verde» pudiera abarcar una gama de sensaciones cromáticas tan exhuberante, al punto de dar la impresión de que cada árbol en particular, o que cada parte de un árbol, exhibiera un matiz de verde completamente diferente de los otros. De regreso a casa, después de revelar y de ampliar los negativos fotográficos sacados en la Patagonia, pude constatar, bastante frustrado, que todo aquel espectáculo cromático de la naturaleza se había reducido drásticamente. A pesar de haber utilizado una cámara profesional, fotómetro independiente y película de un amplio espectro de respuesta, la variación de verdes del paisaje fotografiado me pareció demasiado pobre, además de banal y previsible. Comparando posteriormente mis fotos con otras obtenidas en los mismos lugares por un colega, con quien había compartido el viaje, percibí que, pese a que los resultados parecían igualmente limitados en términos de respuesta cromática, él había obtenido algunos tonos de verde que no existían en mis fotos. Luego, pude saber la razón de ello: mi colega había utilizado otra marca de negativo y otro tipo de papel para la ampliación.

Esta singular experiencia personal me ayudó bastante a entender algunas de las estrategias operativas de la fotografía. Lo que llamamos «color», en verdad, es el resultado perceptivo del comportamiento físico de los cuerpos en relación con la luz que incide sobre ellos y, como tal, una propiedad de cada uno de esos cuerpos. Cada planta, de acuerdo con sus constituyentes materiales, absorbe y refleja de una manera particular los rayos de luz y, por eso, produce su propia gama de verdes. Y las emulsiones fotográficas, por estar compuestas de otros materiales, producen otra gama de verdes. Por esa razón, resulta casi imposible tener en una foto exactamente los mismos colores de un paisaje. El color fotográfico será siempre, por el contrario, una interpretación del color visto, a partir de los componentes materiales propios del film. Ciertamente, la palabra «color» se refiere habitualmente a dos modalidades distintas de fenómenos. Por un lado, un color es una cualidad particular (en términos fenoménicos) o una sensación particular (en términos perceptivos), por lo tanto un hecho de primeridad en términos peirceanos. Por otro lado, un 
color puede también ser un concepto, una categoría, una abstracción del pensamiento, establecida de manera enteramente convencional. Damos el nombre «verde» a una cierta gama de extensiones de ondas luminosas (expresadas en nanómetros), que resultan de determinadas propiedades reflexivas de los materiales. Pero como el espectro cromático visible es continuo, la categorización de los diversos colores no es sólo imprecisa (en las fronteras entre los colores, algunos verán «amarillo» o «azul» lo que otros ven «verde»), sino también arbitraria, lo que explica el hecho de que diferentes culturas clasifiquen de modo distinto las mismas cualidades (los esquimales, por ejemplo, clasifican el único color que llamamos «blanco» en más de una decena de colores).

En nuestro caso, el corolario inevitable de esa constatación es que la película fotográfica sólo puede corresponder al paisaje enfocado con la gama de colores que ella es capaz de producir. La cantidad de verdes que se puede encontrar en la naturaleza es probablemente infinita, porque infinitos son los cuerpos físicos con sus diferentes propiedades reflexivas, pero un determinado patrón fotográfico — digamos un film Kodakolor de 100 ASA, fabricado en la sucursal mexicana de la Kodak y revelado rigurosamente de acuerdo con las instrucciones del fabricante- produce una gama de verdes no sólo finita, sino también tipificada, regular y fija. La totalidad de las imágenes producidas con esa película mostrarán siempre la misma gama de verdes, independientemente del hecho de que el referente sea la Patagonia argentina o las estepas rusas. Los verdes Kodakolor no son, por lo tanto, simples cuali-signos de esa exhuberante experiencia cromática que llamamos «verdor», pero sí colores-tipos, clasificables en catálogos de colores ( $\mathrm{y}$, de hecho, los laboratorios de revelado son calibrados a partir de categorías cromáticas), por lo tanto algo cercano al concepto peirceano de legi-signo. Un film Kodakolor nunca logrará producir un verde singular, como aquél que se puede encontrar sólo en las hojas de una melissa officinalis, observada en la orilla de un lago de la Patagonia, durante una determinada tarde de primavera, luego de haber parado de llover, o como aquél que se puede ver solamente en determinado fresco del Giotto, producido con una tinta fabricada por el propio pintor, a partir del procesamiento de plantas encontradas en la periferia de Florencia. Por el contrario, los verdes Kodakolor se repiten de forma regular y previsible en todas las fotos obtenidas en las mismas condiciones-tipo y es esa regularidad lo que vuelve utilizable a la fotografía, en situaciones de reproducibilidad industrial, para distribución a escala masiva. 
Parte de los problemas relacionados con la comprensión de la fotografía derivan de su encasillamiento tradicional en la categoría peirceana de indice, un encasillamiento que podemos considerar, como mínimo, problemático. Lo que registra la película fotográfica no es exactamente una acción del objeto sobre ella (no hay contacto físico o «dinámico» del objeto con la película), sino el modo particular de absorción y reflexión de la luz por un cuerpo ubicado en un espacio iluminado, tal como una emulsión sensible lo interpreta, basándose sólo en aquella parte de los rayos de luz reflejados por el objeto que pudieran ser captados por la lente y filtrados por los dispositivos internos de la cámara. Se trata de un proceso extraordinadiamente complejo, que se encuentra a algunos años-luz distante de la simplicidad franciscana de los índices visuales clásicos, como la pisada dejada en el suelo por un animal o la impresión digital. En el límite, es posible fotografiar (es decir, registrar en la película) los rayos de luz directamente de su fuente, sin que hayan sido reflejados por objeto alguno. Esto significa que se puede tener fotografía sin objeto, a menos que consideremos, incluso con toda pertinencia, que el verdadero objeto de la fotografía es la luz y no el cuerpo que la refleja. Pensemos en las siguientes paradojas de la fotografía astronómica:

1) La explosión de una estrella, fotografiada en este momento por una cámara acoplada a un telescopio, sucedió, en verdad, varios siglos antes. Lo que ocurre es que la luz emitida por la estrella moribunda tuvo que recorrer una buena parte del universo antes de llegar hasta nuestra emulsión.

2) Por lo menos hay un referente que jamás podrá ser fotografiado: el agujero negro, toda vez que no absorbe ni refleja rayos de luz o cualquier otro tipo de onda. De ahí que una prueba material de la existencia de un agujero negro es imposible.

La fotografía es un proceso enteramente derivado de la técnica, entendiéndose aquí por técnica aquello que Simondon (1969: 12) define como «gesto humano fijado y cristalizado en estructuras que funcionan». En su forma industrial y masiva, la técnica es concebida como un modo de automatización o de tipificación, en el mismo límite del estereotipo. En su acepción más sofisticada, en la investigación científica y en la experimentación artística, por ejemplo, la técnica puede ser también un detonador heurístico, en la medida en que posi- 
bilita al pensamiento ir más allá de aquel otro que la engendró. Si un dispositivo técnico preve «cierto margen de indeterminación», como afirma Simondon (1969: 11), «puede volverse sensible a una información exterior». De cualquier manera, siempre es un conocimiento científico el que, materializado en los medios técnicos, hace existir la fotografía, considerando que, al contrario de las pisadas y de las impresiones digitales, las fotografías no se forman naturalmente, por la mera casualidad del encuentro fortuito entre un objeto y un soporte de registro. La fotografía existe sólo cuando hay una intención explícita de producirla, por parte de uno o más operadores o poseedores del know how específico, y cuando se dispone de un inmenso dispositivo técnico para producirla (cámara, lente, film, iluminación, fotómetro incluido o separado de la cámara, cuarto oscuro de revelación, baños químicos, cronómetros diversos para la marcación del tiempo, etc.), dispositivo desarrollado después de varios siglos de investigación científica y producido en escala industrial por un segmento específico del mercado.

La definición clásica de fotografía como índice constituye, en realidad, una aberración teórica, pues si consideramos que la «esencia ontológica» (expresión tomada de André Bazin, 1981: 9-17) de la fotografía es la fijación del trazo o del vestigio dejado por la luz sobre un material sensible a ella, tendremos obligatoriamente que concluir que todo lo que existe en el universo es fotografía, ya que todo, de algún modo, sufre la acción de la luz. Si me acuesto en una playa para tomar sol, la piel de mi cuerpo «registrará» la acción de los rayos de luz bajo la forma del bronceado o de la quemadura. Si apoyo mi disco predilecto en una mesa junto a una ventana, donde por azar a una determinada hora del día da la luz del sol, el disco se torcerá como el pétalo de una rosa y podremos entonces llamar «fotografía» a ese disco deformado, pues de algún modo ésa es su manera de «registrar», en definitiva, la acción de la luz del sol sobre él. Incluso una simple hoja de papel olvidada en el suelo, expuesta a la luz del sol, después de algún tiempo, se «amarilleará». Pero cuando tomo una fotografía, lo que veo allí no es sólo el efecto de quemadura producido por la luz. Más bien veo una imagen extraordinariamente nítida, intencionalmente moldeada, encuadrada y compuesta, una cierta lógica de distribución de zonas de foco y fuera de foco, una cierta armonía del juego entre claro y oscuro, sin hablar de una inequívoca intención expresiva y significante, que no encuentro jamás en el cuerpo bronceado, en el disco deformado o en el papel amarillento. 
El trazo grabado por la cámara fotográfica (en este caso, la luz reflejada por el objeto) depende de un número extraordinariamente elevado de mediaciones técnicas. En lo que respecta a la cámara, tenemos: la lente con una específica distancia focal, la abertura del diafragma, la abertura del obturador, el punto de foco. En lo que respecta a la emulsión fotográfica: la resolución de granos, la mayor o menos latitud, la amplitud de respuesta cromática, etc. En lo que respecta al papel de ampliación o de impresión: su rugosidad, propiedades de absorción, etc. Esto quiere decir que una foto no es sólamente el resultado de una impresión indicial de un objeto, sino también de las propiedades particulares de la cámara, de la lente, de la emulsión, de la(s) fuente(s) de luz, del papel de reproducción, del baño de revelado, del método de secado, etc. Claro que, como observó correctamente Sonesson (1998), también una pisada es resultado de una interacción variable entre la pata de un animal y el suelo (diferentes tipos de suelo permiten imprimir diferentes tipos de pisadas de un mismo animal). Sin embargo, una pisada, aunque tenga apariencias diferentes conforme al tipo de suelo, será siempre una pisada, pudiendo ser reconocible como tal por un interpretante, mientras que una fotografía sólo será realmente una fotografía si la totalidad de las condiciones técnicas fueran cumplidas con el rigor exigido por los dispositivos mecánico, óptico y químico.

En ese sentido, a diferencia de la pisada, de la impresión digital e incluso de la pintura y del dibujo, la fotografía es el resultado de cálculos complejos y matemáticamente precisos, automatizados en el diseño de la cámara y de la película. El hecho de poder fotografiar sin conocer necesariamente estos cálculos no es muy diferente del hecho de poder modelar formas, de darles textura y brillo, con una computadora, sin tener necesidad de saber programar, pero sólo utilizando programas comerciales. La fotografía es una actividad técnica de extrema precisión, basada en la medición (de la distancia y velocidad del objeto, de la cantidad de luz que penetra en la cámara, del paralaje entre el visor y la ventana del film, del margen de profundidad de campo, del tiempo de revelado, etc.). El fotómetro mide la cantidad de luz que incide en el objeto o que se refleja para la cámara; el termocolorímetro mide la temperatura del color, para adecuar el tipo de film al tipo de iluminación; el diafragma y el obturador deben ser ajustados en una relación de compensación mutua (cuanto más se abre uno, más se cierra el otro), de acuerdo con el valor obtenido por el fotómetro y aún de acuerdo con el grado de sensibilidad de la película. Un error de cálcu- 
lo, por mínimo que sea, y adiós fotografía, por más que el referente esté allí y bien iluminado. El mismo razonamiento sirve también para el cálculo de la profundidad de campo, que establece la cantidad de foco y fuera de foco de una foto, y que es determinado a partir de una compleja ecuación, incluyendo: 1) la distancia del objeto en relación a la cámara; 2) el grado de abertura de diafragma y obturador; 3) la cantidad de luz que ilumina la escena; 4) la distancia focal de la lente utilizada. Los buenos fotógrafos siempre traen en sus bolsos un manual con tablas de profundidad de campo, que es necesario consultar cada vez que surgen dudas sobre si una imagen aparecerá en foco o no. De ahí, por qué una fotografía puede ser considerada, sin vacilar, un signo de naturaleza predominantemente simbólica, perteneciente prioritariamente al dominio de la terceridad peirceana, porque es imagen científica, imagen informada por la técnica, tanto como la imagen digital, no obstante un cierto grado de indicialidad presente en la mayoría de los casos. En otras palabras, fotografía es, antes que nada, el resultado de la aplicación técnica de conceptos científicos acumulados por lo menos a lo largo de cinco siglos de investigaciones en los campos de la óptica, de la mecánica y de la química, así también como de la evolución del cálculo matemático y del instrumental para hacerlo operacional.

En tanto símbolo, según la definición peirceana, la fotografía existe en una relación triádica entre: el signo (la foto, o, si se quiere, el registro), su objeto (la cosa fotografiada) y la interpretación físico-química y matemática. Esa interpretación es un tercero, pudiendo ser «leída» (por otra parte, ésa es la única lectura seria de la fotografía) como la creación de algo nuevo, de un concepto puramente plástico respecto del objeto y su impresión. La verdadera función del aparato fotográfico no es, por lo tanto, registrar una impresión, sino interpretarla científicamente. Esto quiere decir que la impresión fotográfica, cuando existe, no nos es dada en estado bruto y salvaje, sino ya inmensamente mediada e interpretada por el saber científico. Obsérvese cómo el aparato técnico de captación de señales, en ciencias rigurosas como la medicina y la astrofísica, está programado para interpretar y codificar la impresión indicial en elementos sensibles o perceptibles que puedan ser «leídos» por el analista: por ejemplo, ciertos colores pueden representar, por mera convención, determinadas temperaturas del cuerpo o determinadas propiedades de los materiales. Eso quiere decir que se pueden codificar visualmente, como resultado del registro fotográfico, valores obtenidos a través de la medición termodinámica o del análisis físico-químico. 
A decir verdad, tanto el remote sensoring en astrofísica, como el examen no invasivo del interior del cuerpo humano en medicina, modalidades más rigurosas de fotografía para uso científico, son procesos tan codificados que sólo un especialista puede descifrarlos, ya que sólo el especialista detenta el modelo, la clave interpretativa, la convención-patrón. Esas fotos científicas exigen un trabajo de «desciframiento» difícil y altamente especializado, en parte realizado por el propio dispositivo técnico, en parte por el científico que lo opera. Aun así, la ambigüedad y el error son inevitables, por la simple razón de que nunca se pueden inferir con seguridad las cualidades de un objeto al cual no se tiene acceso directo, sino sólo a través de investigación instrumental. En ese sentido los astrofísicos pueden interpretar equivocadamente determinadas señales de los astros y los médicos pueden interpretar mal las respuestas del cuerpo a las ondas de sondeo emitidas por las máquinas. El error es siempre una posibilidad inevitable en estos medios porque el investigador trabaja no con muestras reales, sino con interpretaciones técnicas de las señales emitidas por los cuerpos animados o inanimados, por lo tanto con índices degenerados, transfigurados por la mediación tecno-científica. Por ese motivo, un buen médico no hace nunca un diagnóstico apoyándose sólo en los resultados obtenidos en una radiografía, una ecografía o una tomografía computada, pero sí basándose en un examen completo, al que deben agregarse todavía los exámenes de laboratorio de las muestras reales del cuerpo, para después confrontar e interpretar los diferentes resultados. Por lo tanto, la decisión del médico no es dictada por lo que dice una supuesta evidencia indicial, considerada imprecisa y deformada por la mediación técnica, sino por la interpretación del mayor número posible de evidencias dadas por el cruzamiento de exámenes de distinta naturaleza.

«Un índice —dice Peirce (1978: vol. 2: 315)— implica siempre la existencia de su objeto». Pero en el mundo no existe una inmensa cantidad de elementos que pueden encontrarse en una fotografía. Por ejemplo: el borrón que deja un cuerpo en movimiento rápido; el «temblor» de la cámara; la descomposición en forma de arco iris de los rayos de luz que entran en la lente directamente de la fuente; el estrechamiento o la disminución de tamaño de los objetos que se distancian de la cámara (efecto de perspectiva renacentista); el punto de fuga; el fuera de foco; el recorte o moldura del cuadro (rectangular en la mayoría de las veces, circular en los casos de las lentes «ojo de pescado»); la exclusión de lo que está fuera del cuadro; la alteración de la escala; la granulación, la saturación, la homogeneidad y el contras- 
te de la emulsión de registro; la inversión de tonos y colores producida por el negativo; la deformación óptica producida por ciertas lentes como el gran angular o el teleobjetivo; el blanco y negro; el punto de vista de la cámara; el movimiento congelado; la bidimensionalidad del soporte de registro; el sistema de zonas (Ansel Adams); la deformación lateral (en las cámaras pinhole); la anamorfosis de las figuras planas; la anamorfosis producida por obturadores de plano focal; el filtrado de los reflejos por polarización; el brillo u opacidad del papel de reproducción, y así prosigue, para quedarnos sólo en los aspectos visuales del enunciado. Todos estos elementos icónicos y simbólicos, introducidos por el aparato técnico, no son sólo agregados que se sobreponen al índice, a la impresión del objeto, sino también agentes de transfiguración, deformación e incluso borramiento del trazo. La historia de la fotografía está repleta de ejemplos de fotos cuyo referente, por las más variadas razones técnicas o expresivas, no puede ser identificado, ni siquiera genéricamente. En este caso, se perdió la impresión, aunque haya quedado la fotografía con toda su elocuencia icónica y simbólica.

Hay todavía otro aspecto de la cuestión: la fotografía viene siendo hoy ampliamente utilizada, en el plano de los medios gráficos o electrónicos, como signo genérico, que designa a una clase de imágenes. Véase el ejemplo de los bancos de imágenes (analógicas o digitales) que alimentan en la actualidad la mayor parte de las publicaciones y producciones icónicas. Normalmente, las imágenes, en esos bancos, son solicitadas por lo que ellas tienen de poder de generalización, no por su singularidad. Si una revista, por ejemplo, pretende publicar un artículo sobre deportes de invierno, necesita para ilustrarlo imágenes de gente esquiando. Poco importa quién está esquiando, cuándo, dónde o por qué. Lo que importa es una imagen que signifique genéricamente la acción de esquiar en la nieve. Cuanto más indefinidos y no identificables sean el modelo, el escenario y la ocasión, tanto mejor para la foto, pues tendrá mayor poder de generalización. Los bancos de imágenes guardan hoy varios millones de fotos clasificadas no por epígrafes descriptivos, sino por temas visuales genéricos e identificadas sólo por números de orden. Prácticamente todos los temas pueden ser encontrados en esos bancos: niños, selvas tropicales, establecimientos ganaderos, intervenciones quirúrgicas, reptiles, bibliotecas, nubes, piscinas, lo que se quiera. Esta nueva demanda ha incentivado el desarrollo de otro tipo de fotografía, no «documental», en el sentido habitual de la palabra, sino una fotografía que busca, a través de una imagen singular, simbolizar una clase, una norma o una ley dotada de sentido generalizador. 


\section{Referencias bibliográficas}

BazIN, André (1981). Qu'est-ce que le cinéma? Paris: Éd. du Cerf.

CARANI, Marie (1998). Sémiotique de la photographie post-moderne. Texto presentado en el V Congreso de la Asociación Internacional de Semiótica Visual. Siena. Inédito.

CoHEN, Ted (1989). «Pictorial and Photographic Representation». En International Encyclopedia of Communications, vol. 3. E. Barnouw et alii, eds. Oxford: Oxford Univ. Press.

Dubors, Philippe (1983). L'acte photographique. Paris: Nathan \& Labor. Flusser, Vilém (1985). Filosofia da Caixa Preta. São Paulo: Hucitec.

NADAR (Félix Tournachon) (1981). «My Life as a Photographer». En Photography in Print, Vicki Goldberg, ed. New York: Touchstone.

PeIRCE, Charles Sanders (1978). Collected Papers. Cambridge: Harvard Univ. Press.

Santaella, Lúcia e Nöth Winfried (1998). Imagen: Cognição, Semiótica, Mídia. São Paulo: Iluminuras.

SCHAEFFER, Jean-Marie (1987). L'image précaire. Paris: Seuil.

SimONDON, Gilbert (1969). Du mode d'existence des objets téchniques. Paris: Aubier.

SONESSON, Göran (1993). «Die Semiotik des Bildes: zum Forschungsstand am Anfang der 90er Jahre.» Zeitschrift für Semiotik, $\mathbf{n}^{\circ} 15$.

- (1998). «Postphotography and Beyond: From Mechanical Reproduction to Digital Production». Visio, vol. 4, n. ${ }^{\circ}$ 1, Printemps 1999, 11-36. 